\title{
Varenicline for Tobacco Dependence
}

\author{
J. Taylor Hays, M.D. and Jon O. Ebbert, M.D. \\ Nicotine Dependence Center, Mayo Clinic College of Medicine, Rochester, MN
}

\begin{abstract}
A 57-year-old man with a 60-pack-year history visits his primary care provider because he wants to quit smoking. He has a history of stable coronary artery disease, peripheral vascular disease, and hypertension. He also has severe obstructive lung disease (forced expiratory volume in 1 second, $39 \%$ of the predicted value) with a progressive increase in dyspnea. He has quit smoking and has had numerous relapses; the longest duration of abstinence from smoking was 7 months. Each relapse involved casual smoking to "test himself." During previous attempts to quit, he has used a nicotine patch, a nicotine inhaler, and sustained-release bupropion. He feels motivated to quit smoking because he recently heard about a new medication to aid in quitting, and he wants to improve his health. The patient and his physician discuss the therapeutic options and agree that varenicline (Chantix) may be an option.
\end{abstract}

\section{THE CLINICAL PROBLEM}

Cigarette smoking is the most preventable cause of illness, death, and excess health care costs in the United States, ${ }^{1,2}$ accounting for more than 440,000 deaths annually and $\$ 157$ billion in health-related economic losses. ${ }^{3}$ In the adult population, annual smoking-related deaths are attributed primarily to lung cancer $(125,000$ deaths), ischemic heart disease $(82,000)$, and chronic obstructive pulmonary disease $(65,000) .{ }^{3}$ Cigarette smoking accounts for $30 \%$ of all deaths from cancer in the United States. Smoking is a major risk factor for cancers of the lungs, larynx, oral cavity, pharynx, and esophagus. Cigarette smoking is also causally related to the development of cancers of the bladder, pancreas, uterine cervix, kidney, and stomach, as well as acute myeloid leukemia. ${ }^{4}$ On average, male smokers lose 13.2 years of life expectancy, and female smokers lose 14.5 years. $^{3}$

The prevalence of cigarette smoking among adults in the United States declined from $42.0 \%$ in 1965 to $20.8 \%$ in $2006 .{ }^{5}$ Among adult smokers, 36.5 million (80.8\%) smoke every day, and 8.7 million (19.2\%) smoke some days. The current prevalence of smoking is higher among men $(23.9 \%)$ than among women (18.1\%), generally decreases with increasing education, and is higher among adults living below the poverty level than among those living at or above the poverty level. At the current rate of decline, the United States will not achieve the Healthy People 2010 goal of less than a $12 \%$ prevalence of smoking among adults by $2010 .^{6}$

\section{PATHOPHYSIOLOGY AND EFFECT OF THERAPY}

Nicotine is the addictive substance in tobacco ${ }^{7}$ and it is the primary factor in continued and compulsive tobacco use. The pleasurable effects of nicotine from tobacco (e.g., arousal and relief of anxiety), the association of pleasurable effects with environmental triggers (e.g., after meals, with morning coffee, and during periods of stress), and the presence of craving and

\footnotetext{
Address reprint requests to Dr. Hays at the Mayo Clinic, 200 1st St. SW, Rochester, MN 55905, or at hays.taylor@mayo.edu. 
other uncomfortable symptoms of nicotine withdrawal with the cessation of tobacco use are important factors that both reinforce continued smoking and prevent smokers from achieving sustained abstinence from the use of tobacco. Symptoms and signs of nicotine withdrawal include irritability, frustration, and anger; a dysphoric or depressed mood; anxiety; difficulty concentrating; restlessness; an increased appetite or weight gain; a decreased heart rate; and insomnia. ${ }^{8}$

The pharmacokinetic profile of nicotine delivered through tobacco smoke contributes considerably to nicotine addiction. ${ }^{9}$ After inhalation, cigarette smoking results in rapidly rising nicotine levels because of the large surface area for absorption in the pulmonary circulation. Blood containing nicotine enters the left side of the heart and rapidly reaches the cerebral circulation and receptor targets before being diluted by distribution throughout the systemic circulation. Studies confirm an immediate, rapid rise in nicotine levels from cigarette smoking. 10

The interaction of nicotine with specific receptors in the central nervous system is critical for the development of dependence. Nicotine binds to and causes conformational changes in nicotinic acetylcholine receptors located in multiple areas of the brain (Fig. 1). These pentameric receptors are composed of $\alpha$ and $\beta$ subunits; the nicotinic acetylcholine receptors with the highest affinity for nicotine contain two $\alpha 4$ and three $\beta 2$ subunits. The highest concentrations of the high-affinity $\alpha 4 \beta 2$ nicotinic acetylcholine receptors exist in the mesolimbic dopaminergic system, or the so-called reward center of the brain. ${ }^{11}$ Stimulation of these receptors in this system and the resulting increase in dopamine release mediate the reinforcing effects of nicotine.

Varenicline was developed by modifying the structure of the naturally occurring plant alkaloid cytisine, a partial agonist at the $\alpha 4 \beta 2$ nicotinic acetylcholine receptor that competitively blocks the receptor and only partially activates it (Fig. 1) ${ }^{12}$ Varenicline maintains the partial agonist activity at the $\alpha 4 \beta 2$ nicotinic acetylcholine receptor, with greatly improved penetration in the central nervous system as compared with cytisine. As a non-nicotinic partial agonist of the $\alpha 4 \beta 2$ nicotinic acetylcholine receptors, varenicline binding leads to partial stimulation of receptor-mediated release of dopamine in the reward center and competitive inhibition of receptor binding by nicotine delivered from cigarettes. Consequently, varenicline suppresses the symptoms of nicotine withdrawal and reduces the pharmacologic reward from cigarette smoking. ${ }^{13}$

\section{CLINICAL EVIDENCE}

Several randomized, controlled clinical trials have shown that varenicline is superior to placebo for smoking cessation. ${ }^{14-19}$ Data from three of these trials suggest that varenicline is also more effective than sustained-release bupropion. ${ }^{14-16}$ Two identically designed studies of varenicline efficacy randomly assigned a total of 2052 subjects to receive varenicline at a dose of $1 \mathrm{mg}$ twice a day as compared with sustained-release bupropion at a dose of $150 \mathrm{mg}$ twice a day or placebo. ${ }^{14,15}$ At the end of 12 weeks, the rates of abstinence from smoking were significantly greater among subjects who received varenicline than among subjects who received either sustained-release bupropion or placebo; the 7-day point-prevalence rate of abstinence (i.e., no smoking during the previous 7 days) in both studies was approximately $50 \%$ among subjects who received varenicline, $36 \%$ among subjects who received sustainedrelease bupropion, and $21 \%$ among subjects who received placebo. Fifty-two weeks after the initiation of the study drug (i.e., 9 months after the drug was discontinued), the 7-day pointprevalence rates of abstinence from smoking were approximately $29 \%$ among subjects who had received varenicline, 23\% among subjects who had received sustained-release bupropion, and $15 \%$ among subjects who had received placebo. At 1 year, varenicline was superior to 
placebo in both studies with regard to the rate of continuous abstinence during weeks 9 through 52 , but only one study showed the superior efficacy of varenicline as compared with sustainedrelease bupropion. ${ }^{14}$

Another study of the maintenance of abstinence from smoking assessed the effect of 12 additional weeks of varenicline as compared with placebo in smokers who were abstinent after 12 weeks of receiving open-label varenicline. ${ }^{20}$ The rates of continuous abstinence from smoking among subjects who were randomly assigned to receive an additional 12 weeks of varenicline were superior to those among subjects who received placebo at 1 year (odds ratio, $1.34 ; 95 \%$ confidence interval $[\mathrm{CI}], 1.06$ to $1.69 ; \mathrm{P}=0.02$ ), suggesting that varenicline treatment for up to 6 months may be beneficial. Varenicline diminished craving, withdrawal symptoms, and smoking satisfaction - findings that are consistent with its proposed mechanism of action.

Two open-label trials have compared varenicline with nicotine-replacement therapy. In a convenience sample of 412 patients in the United Kingdom, short-term rates of cessation (4 weeks after the quitting date) were higher with varenicline than with nicotine-replacement therapy (adjusted odds ratio, 1.70; 95\% CI, 1.09 to 2.67). ${ }^{21}$ In an open-label study of 757 patients who were randomly assigned to receive varenicline or a nicotine patch, the biochemically confirmed rate of continuous abstinence (during the last 4 weeks of treatment) was significantly greater with varenicline than with the nicotine patch $(55.9 \%$ vs. $43.2 \%$, $\mathrm{P}<0.001){ }^{22}$ Additional, more methodologically rigorous studies comparing varenicline with nicotine-replacement therapy are needed to make any judgment about their comparative efficacy.

\section{CLINICAL USE}

The clinical practice guidelines of the U.S. Public Health Service have identified pharmacologic agents as either first-line or second-line treatment for tobacco use and dependence and as aids to smoking cessation. ${ }^{23}$ Since 2000, options for first-line pharmacotherapy have included nicotine-replacement therapy and sustained-release bupropion, with the addition of varenicline as a first-line agent in the 2008 guidelines. ${ }^{23}$ All first-line medications are approved by the Food and Drug Administration (FDA) for assistance with smoking cessation.

Varenicline can be chosen as a treatment for patients who have never received pharmacologic treatment for smoking cessation as well as for those in whom other treatments have not been successful. Candidates for treatment should show some evidence of motivation to quit smoking. Varenicline is contraindicated for use during pregnancy and lactation until evidence of its safety in pregnant and nursing women is available.

Clinicians prescribing varenicline should be mindful that treatment results in real-world clinical settings are likely not to be as good as those reported in the published clinical trials for two main reasons. First, the degree of behavioral support provided in the published studies is difficult to replicate in practice. Second, the subjects selected for inclusion in clinical trials are generally healthy and may not be representative of typical clinical populations.

For smokers starting varenicline therapy, a target quitting date should be set for 1 week after the initiation of treatment. Varenicline treatment should be initiated with a 1-week doseadjustment period, with a dose of $0.5 \mathrm{mg}$ once daily on days 1 through $3,0.5 \mathrm{mg}$ twice daily on days 4 through 7 , and the target dose of $1.0 \mathrm{mg}$ twice daily starting on day 8 (i.e., the target quitting date). The 1-week dose-adjustment period reduces nausea as compared with initial therapy at $1 \mathrm{mg}$ twice daily. ${ }^{17}$ Patients should be advised to take each dose with food in order to reduce the risk of nausea. For problematic nausea, the dose may be reduced to $1 \mathrm{mg}$ once 
daily. If nausea resolves at the lower dose, another attempt to increase the dose to the target of $1 \mathrm{mg}$ twice daily is appropriate.

Since more than $80 \%$ of varenicline is excreted unchanged in the urine, ${ }^{24}$ no dose adjustments are required for hepatic impairment. In patients with severe renal impairment (estimated creatinine clearance, $<30 \mathrm{ml}$ per minute), a reduction in the dose to $0.5 \mathrm{mg}$ daily is recommended. Varenicline is effectively removed with hemodialysis and may be used at a similar dose in patients undergoing thrice-weekly hemodialysis. Dose adjustments are not indicated in elderly patients, and no adjustments are required in patients with other coexisting medical illnesses. Because varenicline is minimally metabolized, no clinically meaningful drug-drug interactions have been described.

No special clinical laboratory monitoring is required for patients taking varenicline. Use of the drug has not been associated with any clinically important metabolic, hematologic, or electrocardiographic abnormalities (e.g., liver-test abnormalities, reductions in blood counts, or prolongation of the QT interval, respectively).

Continued therapy with varenicline may be indicated in smokers who have been unable to abstain from smoking after reaching the target quitting date and who are still motivated to quit. Evidence from clinical trials suggests a progressive increase in the 7-day point-prevalence rate of abstinence throughout 6 to 8 weeks of treatment. ${ }^{14,15}$ In patients who are unable to completely abstain from smoking and are not motivated to continue with a quitting plan, discontinuation of therapy is indicated before completion of a 12-week course. Therapy may be discontinued abruptly after 12 to 24 weeks, with no tapering required.

The average retail cost of varenicline at a dose of $1 \mathrm{mg}$ twice daily is $\$ 3$ to $\$ 4$ per day. As with other medication, the retail cost may vary widely. Coverage by pharmacy plans and medical assistance plans is not uniform among states or regions.

Pharmacotherapy for smoking cessation is most effective with brief counseling at the initiation of treatment and periodically during follow-up. The U.S. Preventive Services Task Force has concluded that even "minimal counseling, lasting less than 3 minutes, has been shown to increase overall tobacco abstinence rates" and that "increasing session length and frequency increased efficacy in a dose-response manner." 25 Counseling by telephone may also be provided as an adjunct to pharmacotherapy. ${ }^{26}$

\section{ADVERSE EFFECTS}

As noted above, the most common adverse event attributed to varenicline at a dose of $1 \mathrm{mg}$ twice daily is nausea, occurring in approximately 30 to $50 \%$ of treated subjects (Table 1). ${ }^{14}$, ${ }^{15} \mathrm{In}$ most cases, the nausea is mild or moderate, and discontinuation of treatment because of nausea occurred in approximately $3 \%$ of subjects in the two largest trials. ${ }^{14,15}$ When varenicline is taken with food, the nausea is lessened. Other commonly reported adverse events with varenicline at a dose of $1 \mathrm{mg}$ twice daily are insomnia, abnormal dreams, and gastrointestinal effects (Table 1). Most adverse effects appear to be dose-dependent, and a dose reduction may reduce or eliminate symptoms. On average, $12 \%$ of subjects in clinical trials who received varenicline at a dose of $1 \mathrm{mg}$ twice daily discontinued treatment because of a treatment-related adverse event.

Recently, a number of news articles in the popular media, case reports in medical journals, and voluntary reports from patients to the FDA have described neuropsychiatric adverse events associated with varenicline. ${ }^{27-29}$ Because of these reports, a new warning was added to the varenicline label noting an association of varenicline with an increased risk of neuropsychiatric symptoms, including agitation, depressed mood, suicidal ideation and behavior, and worsening 
of preexisting psychiatric illness. ${ }^{29}$ These adverse effects were noted in patients undergoing nicotine withdrawal as well as in some patients who were still smoking.

Since cigarette smoking is itself associated with suicidal behavior, ${ }^{30}$ it remains unclear whether these neuropsychiatric symptoms are causally related to varenicline use. However, patients receiving varenicline and their caregivers should be alerted about these potential effects, and prescribers need to monitor patients closely if adverse behavioral effects are reported by the patient or family. If any symptoms or other changes in behavior that are not typical for the patient are observed, the patient should be advised to stop taking varenicline and assessed to determine whether the drug should be permanently discontinued. Since varenicline was not tested in patients with psychiatric disorders (e.g., schizophrenia, bipolar disorder, or current major depression), its safety in these patients has not been assessed, and it should be used only with caution in such persons.

Adverse events (e.g., unexplained alterations in consciousness or visual disturbances) reported to the FDA during the postmarketing period and summarized by a nonprofit medication-safety group also suggest safety concerns about the use of varenicline while driving or operating heavy machinery. ${ }^{31}$ Prompted by these reports, the Federal Aviation Administration determined that pilots and air-traffic controllers may not use varenicline. Similar caution regarding the use of varenicline has been advised by the organization overseeing interstate commercial truck and bus drivers. Until a detailed analysis of these adverse events to determine their cause is completed, varenicline should not be used in medically certified pilots, air-traffic controllers, or other people for whom the examining clinician believes the use of varenicline would create a safety concern.

\section{AREAS OF UNCERTAINTY}

Results of clinical trials ${ }^{14-16}$ and indirect evidence from a meta-analysis ${ }^{32}$ confirm that the efficacy of varenicline is similar to that of other first-line medications indicated for smoking cessation. However, additional clinical experience and evidence of comparative efficacy from clinical trials will be required to establish whether there is a hierarchy of efficacy for varenicline as compared with other first-line treatments for smokers who are trying to quit.

All published evidence regarding varenicline to date involves the use of this agent as monotherapy. Combinations of various first-line treatments may boost rates of smoking abstinence over single-agent therapy, ${ }^{33,34}$ but no studies of varenicline have examined this concept.

Because sustained-release bupropion and varenicline have different therapeutic targets and no important drug interactions, combined therapy may provide an option for treatment in smokers who have had relapses while receiving other first-line treatments. Combined treatment with varenicline and nicotine-replacement therapy is more problematic because the risk and severity of nausea - an adverse effect seen with both drugs - may increase when the drugs are combined. Nicotine-replacement therapy and varenicline may be tolerable for some patients and may be preferable, particularly during the initial dose-adjustment period of varenicline, when withdrawal symptoms may be most severe and the risk of relapse is highest. However, combination therapy with varenicline and nicotine-replacement therapy is not advised until studies ensuring safety and efficacy have been published.

The optimal length of therapy with varenicline has not been defined. In a maintenance-ofabstinence trial, 6 months of varenicline treatment resulted in better rates of abstinence at both 6 and 12 months than 12 weeks of treatment. ${ }^{20}$ Varenicline treatment for up to 1 year was also superior to placebo. ${ }^{35}$ Relapse prevention is the critical issue to be tackled in order to achieve significant reductions in the prevalence of smoking among adults. Additional studies of smokers who quit but who remain at risk for relapse are needed; these studies may determine whether prolonged therapy will result in superior long-term rates of abstinence from smoking. 
As noted above, the safety of varenicline in patients with certain coexisting psychiatric conditions has not been established, and recent warnings recommend caution when using varenicline in these circumstances. Patients with clinically significant or unstable medical conditions such as cardiovascular disease and chronic lung disease are often most in need of aids for smoking cessation, but they were not included in the pivotal trials of varenicline. Since varenicline has not been associated with clinically significant cardiopulmonary adverse effects, its use in patients with these conditions is likely to be safe. Trials are currently being conducted to test the efficacy and safety of varenicline in smokers with coexisting cardiovascular disease and mild-to-moderate chronic obstructive lung disease, ${ }^{36,37}$ but no published results are available.

\section{GUIDELINES}

The current U.S. Public Health Service clinical practice guidelines for the treatment of tobacco dependence recommend varenicline as one option for first-line therapy. ${ }^{23}$ Similarly, current guidelines of the United Kingdom's National Health Service ${ }^{38}$ and the Royal Australian College of General Practitioners ${ }^{39}$ recommend varenicline with appropriate behavioral support for smokers who are motivated to quit smoking. Other professional societies also include varenicline among the recommended forms of pharmacotherapy for the treatment of tobacco dependence. ${ }^{40,41}$

\section{RECOMMENDATIONS}

The patient in the clinical vignette has many of the chronic conditions classically associated with tobacco use, and his history reflects the "hardening" of smokers (i.e., increasing resistance to cessation) that has been hypothesized. ${ }^{42}$ Although retreatment with one or more of the drugs that he has previously used is an option, his motivation to quit now may be enhanced by the fact that varenicline is a treatment option that he has not tried. We would recommend varenicline along with behavioral counseling to give him the best opportunity for abstinence from smoking. He has no contraindications for varenicline treatment with the typical 1-week period of dose adjustment up to the target dose of $1 \mathrm{mg}$ twice daily. Similar to all patients receiving varenicline, he will need to be apprised of the potential for adverse neuropsychiatric effects, and he should be advised to report these symptoms immediately if they occur. If he continues to smoke after reaching his target quitting date, we would advise continuing treatment as long as he remains engaged in a plan that will lead to abstinence in the first 8 to 10 weeks of treatment. Given his history of repeated episodes of relapse and heavy cigarette use, he may remain at an increased risk for relapse for many weeks after quitting. We would plan to continue his treatment with varenicline for 6 months, with periodic follow-up for counseling and assessment for adverse effects and to ensure ongoing support for abstinence.

\section{Acknowledgments}

Dr. Hays reports receiving grant support from Pfizer, the Department of Veterans Affairs, the Mayo Clinic Foundation for Medical Education and Research, and the American Legacy Foundation, which is supported by funds from the 1998 Master Settlement Agreement with U.S. tobacco companies; and Dr. Ebbert, grant support from the National Institutes of Health and the Flight Attendant Medical Research Institute.

\section{References}

1. Prevalence of current cigarette smoking among adults and changes in prevalence of current and some day smoking — United States, 1996-2001. JAMA 2003;289:2355-6. [PubMed: 12746348]

2. Mokdad AH, Marks JS, Stroup DF, Gerberding JL. Actual causes of death in the United States, 2000. JAMA 2004;291:1238-45. [Errata, JAMA 2005;293:293-4, 298.]. [PubMed: 15010446] 
3. Annual smoking-attributable mortality, years of potential life lost, and economic costs - United States, 1995-1999. MMWR Morb Mortal Wkly Rep 2002;51:300-3. [PubMed: 12002168]

4. Department of Health and Human Services. The health consequences of smoking: a report of the Surgeon General. Atlanta: National Center for Chronic Disease Prevention and Health Promotion; 2004.

5. Cigarette smoking among adults — United States, 2006. MMWR Morb Mortal Wkly Rep 2007;56:1157-61. [PubMed: 17989644]

6. Mendez D, Warner KE. Smoking prevalence in 2010: why the Healthy People goal is unattainable. Am J Public Health 2000;90:401-3. [PubMed: 10705858]

7. Department of Health, Education, and Welfare. The health consequences of smoking: nicotine addiction: a report of the Surgeon General: 1988. Washington, DC: Government Printing Office; 1988. (DHHS publication no. (CDC) 88-8406.)

8. Diagnostic and statistical manual of mental disorders. 4. Washington, DC: American Psychiatric Association; 1994. rev.: DSM-IV

9. O’Brien, CP. Drug addiction and drug abuse. In: Brunton, LL.; Lazo, JS.; Parker, KL., editors. Goodman \& Gilman's The pharmacologic basis of therapeutics. 11. New York: McGraw-Hill; 2006. p. 607-28.

10. Henningfield JE, Stapleton JM, Benowitz NL, Grayson RF, London ED. Higher levels of nicotine in arterial than in venous blood after cigarette smoking. Drug Alcohol Depend 1993;33:23-9. [PubMed: 8370337]

11. Watkins SS, Koob GF, Markou A. Neural mechanisms underlying nicotine addiction: acute positive reinforcement and withdrawal. Nicotine Tob Res 2000;2:19-37. [PubMed: 11072438]

12. Slater YE, Houlihan LM, Maskell PD, et al. Halogenated cytisine derivatives as agonists at human neuronal nicotinic acetylcholine receptor subtypes. Neuropharmacology 2003;44:503-15. [PubMed: 12646287]

13. Coe JW, Brooks PR, Vetelino MG, et al. Varenicline: an alpha4beta2 nicotinic receptor partial agonist for smoking cessation. J Med Chem 2005;48:3474-7. [PubMed: 15887955]

14. Jorenby DE, Hays JT, Rigotti NA, et al. Efficacy of varenicline, an alpha4beta2 nicotinic acetylcholine receptor partial agonist, vs placebo or sustained-release bupropion for smoking cessation: a randomized controlled trial. JAMA 2006;296:56-63. [Erratum, JAMA 2006;296:1355.]. [PubMed: 16820547]

15. Gonzales D, Rennard SI, Nides M, et al. Varenicline, an alpha4beta2 nicotinic acetylcholine receptor partial agonist, vs sustained-release bupropion and placebo for smoking cessation: a randomized controlled trial. JAMA 2006;296:47-55. [PubMed: 16820546]

16. Nides M, Oncken C, Gonzales D, et al. Smoking cessation with varenicline, a selective alpha4beta2 nicotinic receptor partial agonist: results from a 7-week, randomized, placebo- and bupropioncontrolled trial with 1-year follow-up. Arch Intern Med 2006;166:1561-8. [PubMed: 16908788]

17. Oncken C, Gonzales D, Nides M, et al. Efficacy and safety of the novel selective nicotinic acetylcholine receptor partial agonist, varenicline, for smoking cessation. Arch Intern Med 2006;166:1571-7. [PubMed: 16908789]

18. Tsai ST, Cho HJ, Cheng HS, et al. A randomized, placebo-controlled trial of varenicline, a selective alpha4beta2 nicotinic acetylcholine receptor partial agonist, as a new therapy for smoking cessation in Asian smokers. Clin Ther 2007;29:1027-39. [PubMed: 17692719]

19. Nakamura M, Oshima A, Fujimoto Y, Maruyama N, Ishibashi T, Reeves KR. Efficacy and tolerability of varenicline, an alpha4beta2 nicotinic acetylcholine receptor partial agonist, in a 12-week, randomized, placebo-controlled, dose-response study with 40-week follow-up for smoking cessation in Japanese smokers. Clin Ther 2007;29:1040-56. [PubMed: 17692720]

20. Tonstad S, Tonnesen P, Hajek P, Williams KE, Billing CB, Reeves KR. Effect of maintenance therapy with varenicline on smoking cessation: a randomized controlled trial. JAMA 2006;296:64-71. [PubMed: 16820548]

21. Stapleton JA, Watson L, Spirling LI, et al. Varenicline in the routine treatment of tobacco dependence: a pre-post comparison with nicotine replacement therapy and an evaluation in those with mental illness. Addiction 2008;103:146-54. [PubMed: 18028247] 
22. Aubin HJ, Bobak A, Britton JR, et al. Varenicline versus transdermal nicotine patch for smoking cessation: results from a randomised open-label trial. Thorax 2008;63:717-24. [PubMed: 18263663]

23. Fiore, MC.; Jaen, CR.; Baker, TB., et al. Clinical practice guideline: treating tobacco use and dependence: 2008 update. Rockville, MD: Department of Health and Human Services; May. 2008

24. Obach RS, Reed-Hagen AE, Krueger SS, et al. Metabolism and disposition of varenicline, a selective alpha4beta2 acetylcholine receptor partial agonist, in vivo and in vitro. Drug Metab Dispos 2006;34:121-30. [PubMed: 16221753]

25. U.S. Preventive Services Task Force. AHRQ publication no. 04-0526. Rockville, MD: Agency for Healthcare Research and Quality; Nov2003 [Accessed October 10, 2008]. Counseling to prevent tobacco use and tobacco-caused disease: recommendation statement. http://www.ahrq.gov/clinic/3rduspstf/tobacccoun/tobcounrs.pdf

26. Stead LF, Perera R, Lancaster T. Telephone counselling for smoking cessation. Cochrane Database Syst Rev 2006;3:CD002850. [PubMed: 16855992]

27. Kohen I, Kremen N. Varenicline-induced manic episode in a patient with bipolar disorder. Am J Psychiatry 2007;164:1269-70. [PubMed: 17671294]

28. Freedman R. Exacerbation of schizophrenia by varenicline. Am J Psychiatry 2007;164:1269. [PubMed: 17671295]

29. Center for Drug Evaluation and Research. Varenicline (marketed as Chantix) information: FDA alert. Rockville, MD: Food and Drug Administration; 2008 [Accessed October 10, 2008]. http://www.fda.gov/Cder/drug/infopage/varenicline/default.htm

30. Kessler RC, Berglund PA, Borges G, et al. Smoking and suicidal behaviors in the National Comorbidity Survey-Replication. J Nerv Ment Dis 2007;195:369-77. [PubMed: 17502801]

31. Strong safety signal seen for new varenicline risks. Horsham, PA: Institute for Safe Medication Practices; 2008 [Accessed October 10, 2008]. http://www.ismp.org/docs/vareniclineStudy.asp

32. Wu P, Wilson K, Dimoulas P, Mills EJ. Effectiveness of smoking cessation therapies: a systematic review and meta-analysis. BMC Public Health 2006;6:300. [PubMed: 17156479]

33. Jorenby DE, Leischow SJ, Nides M, et al. A controlled trial of sustained-release bupropion, a nicotine patch, or both for smoking cessation. N Engl J Med 1999;340:685-91. [PubMed: 10053177]

34. Silagy C, Lancaster T, Stead L, Mant D, Fowler G. Nicotine replacement therapy for smoking cessation. Cochrane Database Syst Rev 2004;3:CD000146. [PubMed: 15266423]

35. Williams KE, Reeves KR, Billing CB Jr, Pennington AM, Gong J. A double-blind study evaluating the long-term safety of varenicline for smoking cessation. Curr Med Res Opin 2007;23:793-801. [PubMed: 17407636]

36. Bethesda, MD: National Library of Medicine; 2008 [Accessed October 10, 2008]. Effectiveness and safety of varenicline in smokers with cardiovascular disease who wish to quit smoking (ClinicalTrials.gov no. NCT00282984). http://clinicaltrials.gov/show/NCT00282984

37. Bethesda, MD: National Library of Medicine; 2008 [Accessed October 10, 2008]. Smoking cessation in subjects with mild-to-moderate chronic obstructive pulmonary disease (COPD) (ClinicalTrials.gov no. NCT00285012.). http://clinicaltrials.gov/show/NCT00285012

38. Varenicline for smoking cessation. London: National Institute for Health and Clinical Excellence (NICE); 2007 [Accessed October 10, 2008]. http://www.nice.org.uk/guidance/page.redirect?o=350181

39. Zwar, N.; Richmond, R.; Borland, R., et al. Smoking cessation pharmacotherapy: an update for health professionals. Melbourne, Australia: Royal Australian College of General Practitioners; 2007.

40. Tonnesen P, Carrozzi L, Fagerström KO, et al. Smoking cessation in patients with respiratory diseases: a high priority, integral component of therapy. Eur Respir J 2007;29:390-417. [PubMed: 17264326]

41. Graham I, Atar D, Borch-Johnsen K, et al. European guidelines on cardiovascular disease prevention in clinical practice: executive summary. Eur Heart J 2007;28:2375-414. [PubMed: 17726041]

42. Irvin JE, Brandon TH. The increasing recalcitrance of smokers in clinical trials. Nicotine Tob Res 2000;2:79-84. [PubMed: 11072444] 


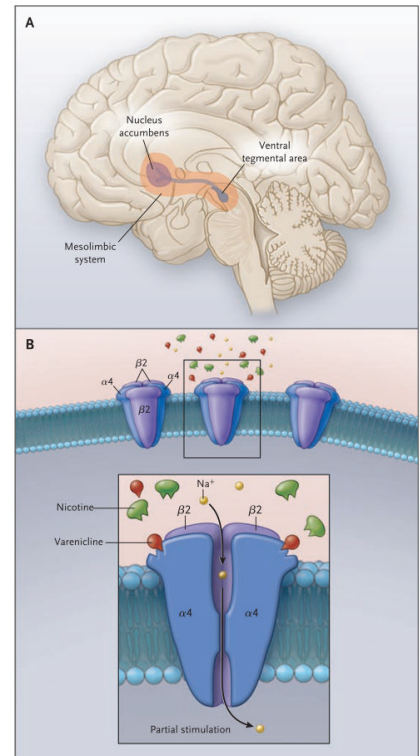

Figure 1. The Actions of Nicotine and Varenicline in the Brain The principal site of nicotine action in the brain is the mesolimbic system (Panel A). Nicotine stimulates dopaminergic neurons located in the ventral tegmental area, increasing dopamine release in the nucleus accumbens. Nicotine interacts with nicotinic acetylcholine receptors, which are pentameric ion channels located in the mesolimbic system and elsewhere (Panel B). The highest-affinity nicotinic acetylcholine receptors consist of two $\alpha 4$ subunits and three $\beta 2$ subunits. Nicotine binds to and causes a conformational change in the $\alpha 4 \beta 2$ nicotinic acetylcholine receptor, increasing sodium $\left(\mathrm{Na}^{+}\right)$influx. Varenicline is a partial agonist of the $\alpha 4 \beta 2$ nicotinic acetylcholine receptor that causes partial stimulation while it competitively inhibits nicotine binding. 


\section{Table 1}

Varenicline as Compared with Placebo.*

\begin{tabular}{|lcr|}
\hline Variable & Varenicline & Placebo \\
& \% of subjects \\
Adverse effect & & \\
Nausea & 35.8 & 11.2 \\
Insomnia & 22.0 & 12.7 \\
Abnormal dreams & 14.4 & 5.0 \\
Headache & 16.8 & 14.3 \\
Other gastrointestinal effects ${ }^{\dagger}$ & 22.5 & 11.8 \\
Discontinuation of study drug due to treatment-related adverse event & 12.0 & 8.1 \\
\hline
\end{tabular}

* Data shown are the mean percentages of subjects reporting the adverse effect in randomized trials of varenicline at a dose of 1 mg twice daily. Adverse events reported in $5 \%$ or more of subjects receiving varenicline at this dose are included.

${ }^{\dagger}$ Other gastrointestinal effects were vomiting, constipation, diarrhea, flatulence, and dyspepsia. 